\title{
Tip110 interacts with YB-1 and regulates each other's function
}

\author{
Khalid Amine Timani, Ying Liu and Johnny J He*
}

\begin{abstract}
Background: Tip110 plays important roles in tumor immunobiology, pre-mRNA splicing, expression regulation of viral and host genes, and possibly protein turnover. It is clear that our understanding of Tip110 biological function remains incomplete.

Results: Herein, we employed an immunoaffinity-based enrichment approach combined with protein mass spectrometry and attempted to identify Tip110-interacting cellular proteins. A total of 13 major proteins were identified to be complexed with Tip110. Among them was Y-box binding protein 1 (YB-1). The interaction of Tip110 with YB-1 was further dissected and confirmed to be specific and involve the N-terminal of both Tip110 and YB-1 proteins. A HIV-1 LTR promoter-driven reporter gene assay and a CD44 minigene in vivo splicing assay were chosen to evaluate the functional relevance of the Tip110/YB-1 interaction. We showed that YB-1 potentiates the Tip110/ Tat-mediated transactivation of the HIV-1 LTR promoter while Tip110 promotes the inclusion of the exon 5 in CD44 minigene alternative splicing.

Conclusions: Tip110 and YB-1 interact to form a complex and mutually regulate each other's biological functions.

Keywords: HIV-1 Tat, Tip110, YB-1, Alternative Splicing, CD44, Transcription
\end{abstract}

\section{Background}

HIV-1 Tat-interacting protein of $110 \mathrm{kDa}$ (Tip110), also known as squamous cell carcinoma antigen recognized by $\mathrm{T}$ cells 3 (SART3), was initially identified from a human myeloid cell line KG-1 cDNA library in 1995 [1]. Several important biological functions have been attributed to this gene/protein since its identification. A considerably elevated level of Tip110 is detected in a variety of human cancers [2-9], it has been proposed as a tumor antigen for immunotherapy. In addition, Tip110 binds to small nuclear RNA U6 and regulates eukaryotic pre-mRNA splicing $([10,11]$ and our unpublished data). It also preferentially regulates the inclusion of exon 1a and skipping of exon $1 \mathrm{~b}$ of the OCT4 gene [12]. Alteration of splicing components induced by a mutation in early grey, a Tip110 orthrologue in zebrafish leads to organ-specific defects and embryonic death [13], suggesting an important role of Tip110 in development. Furthermore, Tip110 is directly involved in expression regulation of viral and host genes including HIV-1, androgen receptor, and stem cell factors CYMC, GATA-2,

\footnotetext{
* Correspondence: johnny.he@unthsc.edu

University of North Texas Health Science Center, 3500 Camp Bowie Blvd., Fort Worth, TX 76107, USA
}

NANOG, and SOX2 [14-17]. Lastly, Tip110 is shown to interact with ubiquitin-specific peptidases (USP) such as USP4 and regulate protein degradation [18]. It is clear that our understanding of Tip110 biological function is still rapidly evolving.

To further understand the biological function of Tip110, we wished to begin by identifying potential cellular proteins that interacted with Tip110. We took the immunoaffinitybased enrichment approach, followed by protein mass spectrometry. We isolated a total of 13 Tip110-binding proteins. Among them was Y-box binding protein 1 (YB-1). In this study, we characterized Tip110/YB-1 interaction and its impacts on each other's function.

\section{Methods}

Cell culture and transfection 293T cells were purchased from American Tissue Culture Collection (ATCC) and grown in Dulbecco's modified Eagle's medium containing $10 \%$ fetal bovine serum. The cell line was maintained in $100 \mathrm{IU} / \mathrm{ml}$ penicillin $-100 \mu \mathrm{g} / \mathrm{ml}$ streptomycin and incubated at $37^{\circ} \mathrm{C}$ in $5 \% \mathrm{CO}_{2}$. Cells were transfected using the standard calcium phosphate precipitation method. The 
chloramphenicol acetyltransferase (CAT) reporter gene assay was performed as described previously [14].

Plasmids Construction of pTip110-His, pTip110-HA, $\Delta \mathrm{CT}, \triangle \mathrm{RRM}, \Delta \mathrm{NT}, \Delta \mathrm{NLS}$, pTip110-GFP, pTat-Myc plasmids have been described elsewhere $[14,15]$. The pCD44 minigene plasmid was generously provided by Dr. Stefan Stamm of University of Kentucky, Lexington, KY). The full length YB-1 cDNA (1-324aa) and the deletion mutants pYB- $1 \Delta \mathrm{C}$ (1-128aa) and pYB- $1 \Delta \mathrm{N}$ (129-324aa) were generated by standard PCR techniques and inserted into the mammalian expression plasmid pCMV-Myc by using the pSPORT6-YB-1 plasmid as a template. Primers were for pYB-1-Myc: 5' -ATC CGA GAT CTA TAG CAG CGA GGC CGA GAC-3' and 5'-AAT ACC TCG AGT TAC TCA GCC CCG CCC TGC TC-3'; for pYB-1 $\triangle$ C: 5'-ATC CGA GAT CTA TAG CAG CGA GGC CGA GAC-3' and 5'-AAT ACC TCG AGT TAA GGA CCT GTA ACA TTT GCT GC-3'; for pYB-1 $\triangle \mathrm{N}$ : 5' -ATC CGA GAT CTA TGG TGG TGT TCC AGT TCA AGG-3' and 5'-AAT ACC TCG AGT TAC TCA GCC CCG CCC TGC TC-3'. Respective Bgl II and Xho I restriction sites in the primers were italicized.

Mass spectrometry 293T cells were mock or pTip110$\mathrm{HA}$ transfected. At $72 \mathrm{hr}$ post-transfection, the cells were lysed with WCEB buffer (50 mM Tris.HCl, pH 8.0, 280 $\mathrm{mM} \mathrm{NaCl}, 0.5 \%$ NP-40, $0.2 \mathrm{mM}$ EDTA, 2 mM EGTA, $10 \%$ glycerol, $2 \mathrm{mM}$ PMSF and protease inhibitors) and applied to the anti-HA affinity matrix column (Roche). The column was washed with 20 bed-volumes, using washing buffer $(20 \mathrm{mM}$ Tris. $\mathrm{HCl}, \mathrm{pH}$ 7.5, $0.1 \mathrm{M} \mathrm{NaCl} ; 0.1 \mathrm{mM}$ EDTA) and then incubated at $37^{\circ} \mathrm{C}$ with elution buffer containing HA peptide $(1 \mathrm{mg} / \mathrm{ml})$ for $15 \mathrm{~min}$. A portion of the elutes was mixed with $4 \times$ SDS-PAGE loading buffer and then resolved by $10 \%$ SDS-PAGE, and the remaining elutions were analyzed by LC-MS/MS on a waters Q-Tof Ultima mass spectrometer at the Yale Cancer Center Mass spectroscopy and W.M. Keck Foundation and Biotechnology, followed by an automated Mascot algorithm against the NCBI database.

Immunoprecipitation and Western blot analysis 293T cells were transfected with plasmids as indicated and harvested $72 \mathrm{hr}$ post transfection. The cells were lysed in WCEB lysis buffer. Lysates were cleared of cell debris by centrifugation. Antibodies $(1-2 \mu \mathrm{g} / \mathrm{mg}$ protein) were added to the lysates and incubated at $4{ }^{\circ} \mathrm{C}$ on a rotating device for $2 \mathrm{hr}$, and protein A agarose beads (Upstate, Temecula, CA) were added to precipitate the complex. Pelleted beads were washed and suspended in $4 \times$ SDS loading buffer, boiled and used for SDS-PAGE. The proteins were transferred onto the HyBond-P membrane (Amersham, UK). The membrane was probed with primary antibodies and the appropriate peroxidase-labeled secondary antibody, then visualized with an ECL system.
CD44 minigene splicing assay 293T cells were plated on 6-well plates and grown to $60-70 \%$ confluence and then transfected with the pCD44-v5 splicing reporter, pTip110-HA, pYB-1 or pYB-1 mutant plasmids. At $72 \mathrm{hr}$ post transfection, total RNA was isolated using Trizol (Invitrogen, Carlsbad, CA), followed by acid:phenol extraction to prevent residual DNA from being used as a PCR template. Total RNA $(0.6 \mu \mathrm{g})$ was used for reverse transcriptase (RT)-PCR using the Titan one tube RT-PCR system (Roche, Indianapolis, IN) and primers 5'-GAG GGA TCC GCT CCT GCC CC-3' and 5'-CTC CCG GGC CAC CTC CAG TGC C-3' and a program of 35 cycles of $94^{\circ} \mathrm{C}$ for $60 \mathrm{~s}, 61^{\circ} \mathrm{C}$ for $60 \mathrm{~s}$, and $72^{\circ} \mathrm{C}$ for 90 s. The RT-PCR products were separated on a $1 \%$ agarose gel.

Data analysis where appropriate, values were expressed as mean \pm SD of triplicate experiments. All comparisons were made based on the control using two-tailed Student's $t$-test. A $p$ value of $<0.05$ was considered statistically significant (*), $p<0.01$ highly significant $(* *)$ and $p<0.001$ strongly significant $(* *)$. All data were representative of multiple repeated experiments.

\section{Results}

\section{Identification of Tip110-interacting proteins}

To identify Tip110-interacting protein, 293T cells were transfected with pTip110-HA plasmid. Cell lysates were prepared and passed through a HA-affinity column. Following extensive washes, the bound proteins were eluted and fractionated on the SDS-PAGE. In parallel, cell lysates from pcDNA3-transfected cells were also included. Coomassie blue staining revealed several protein bands whose intensity differed between samples from Tip110$\mathrm{HA}$ and pcDNA3 (Figure 1A). Those proteins were recovered for mass spectrometric identification. Besides the bait protein Tip110 itself, there were 13 major proteins identified (Table 1). Those included cytoskeletal proteins, heat shock proteins, ribonucleoproteins, skin proteins and two ungrouped protein importin- $2 \alpha$ and $Y$ box binding protein 1 (YB-1). The interactions of Tip110 with all of those proteins were further examined and confirmed by immunoprecipitation followed by Western blot analysis (data not shown and see below). In the study, we chose to focus on YB-1 protein, as YB-1 and Tip110 appear to possess several similar functions. First, both Tip110 and YB-1 protein bind to RNA and are involved in post-transcriptional regulation such as pre-mRNA splicing $[19,20]$. Second, both Tip110 and YB-1 are highly expressed in some cancers [21]. Third, both Tip110 and YB-1 interact with HIV1 Tat protein and regulate HIV-1 gene expression. Lastly, both Tip110 and YB-1 are regulated by transcription factor c-Myc $[16,22]$. Thus, all these observations imply that Tip110 forms complex with YB-1 and regulate each other's function and suggest potential physiological significance of this interaction. 


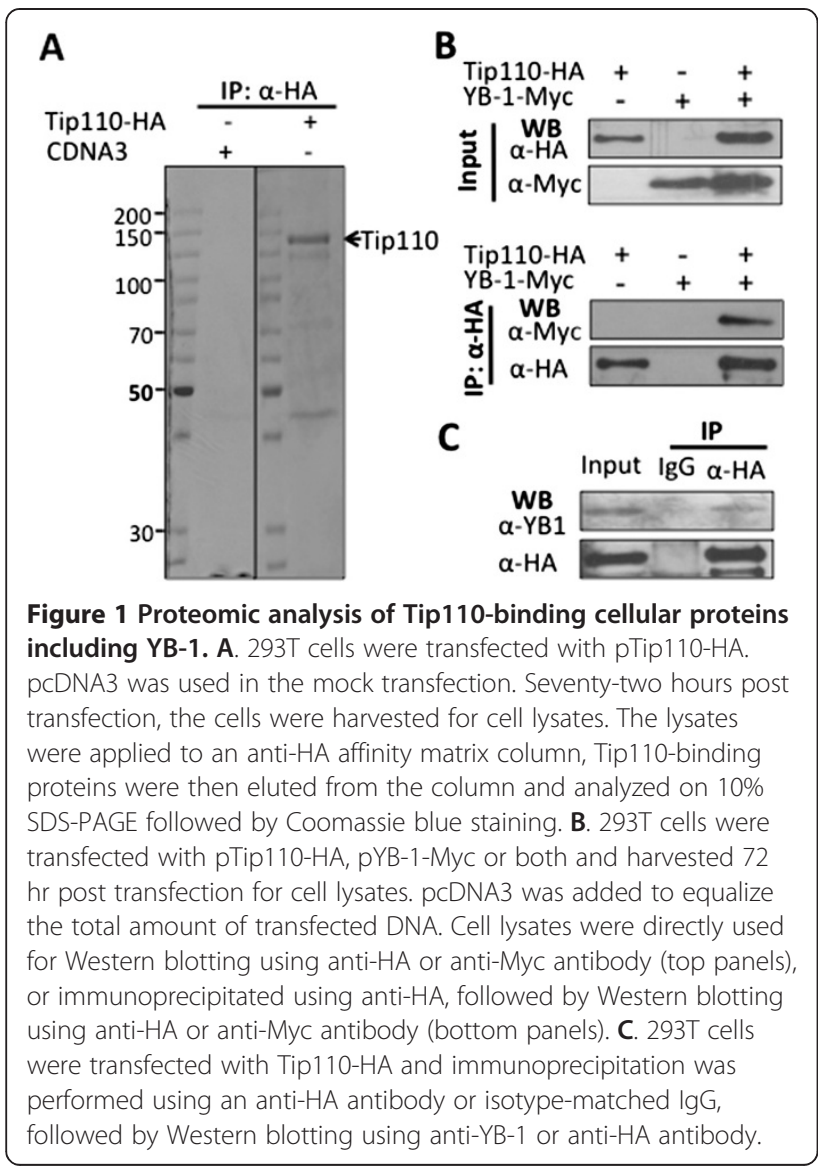

Tip110 interacted with YB-1 and its molecular determinants To confirm Tip110 interaction with YB-1, 293T cells were transfected with pTip110-HA, pYB-1-Myc, or both. Western blot analysis using anti-HA or anti-Myc antibody showed that both Tip110 and YB-1 were expressed in $293 \mathrm{~T}$ cells (Figure 1B, top panels). Immunoprecipitation of cell lyastes using anti-HA antibody, followed by Western blotting with anti-Myc or anti-HA antibody showed that YB-1 was detected in the Tip110immunoprecipitates only when Tip110-HA and Myc-YB-1 were co-expressed (Figure 1B, bottom panels). Immunoprecipitation and Western blotting were performed with the very same antibody to ensure the immnoprecipitation efficiency of the antibody. Similar experiments were also performed with 293T cells transfected with pTip110-HA only. Endogenous YB-1 was also detected in the Tip110immunoprecipitates of Tip110-HA expression cells, but not present with the isotype IgG-immunoprecipitates (Figure 1C). Those results suggest that Tip110 complexed with YB-1 in vivo.

To further determine the specificity of the interaction, we took advantage of a series of Tip110 mutants that contained deletions of the N-terminal HAT-domain $(\Delta \mathrm{NT})$, RRM domain $(\triangle R R M)$, NLS domain $(\triangle N L S)$, and the Cterminal domain $(\Delta C T)$ (Figure 2A) [14]. 293T cells were
Table 1 Tip110-interacting proteins identified by IP followed by mass spectrometry

\begin{tabular}{ll}
\hline Groups & Proteins \\
\hline Cytoskeletal Proteins & \\
& Actin \\
& Keratin- $1 / 2$ \\
& Tubulin $\alpha / \beta$ \\
& Synaptagmin $2 a$
\end{tabular}

$\begin{array}{ll} & \text { HSP A8 (71 kDa) } \\ & \text { HSP A1B (70 kDa) } \\ \text { Ribonucleoproteins } & \text { hnRNPA2-B1 } \\ & \text { hnRNP A1 } \\ & \text { hnRNP U } \\ \text { Skin Proteins } & \text { Hornerin } \\ & \text { Filaggrin } \\ \text { Ungrouped Proteins } & \text { Importin-2a } \\ & \text { YB-1 }\end{array}$

The proteins were organized into groups based on their functions.

transfected with pTip110-HA or each of the Tip110 mutants. Tip110 and its mutants were expressed at the expected molecular weights (Figure 2B, top two panels). Immunoprecipitation with anti-YB-1 antibody, followed by Western blot analysis using anti-Tip110 antibody showed detection of Tip110, $\triangle \mathrm{CT}, \triangle \mathrm{RRM}$ and $\triangle \mathrm{NLS}$, but not $\triangle \mathrm{NT}$ in the YB-1 immunoprecipitates (Figure 2B, bottom two panels). Similarly, we performed binding experiments of Tip110 to deletion mutants of YB-1 lacking the N-terminal (aa1-129, YB-1 $\Delta \mathrm{N}$ ) or the C-terminal domains (aa130-324, $\mathrm{YB}-1 \Delta \mathrm{C}$ ) (Figure 3A) and found that deletion of the $\mathrm{N}$ terminal domain of YB-1 (YB-1 $\Delta \mathrm{N})$ prevented its complex formation with Tip110 (Figure 3B). Taken together, these results further confirmed the complex formation between Tip110 and YB-1 (Table 1) and suggest that the N-terminal domains of both Tip110 and YB-1 are directly involved in the complex formation.

\section{YB-1 modulated Tip110/Tat-mediated transactivation of the HIV-1 LTR promoter}

Tip110 interacts with the HIV-1 Tat viral protein and transactivates the HIV-1 LTR promoter [14,23]. Thus, we chose a LTR promoter-driven reporter gene chloramphenicol acetyltransferase (CAT) to determine the effects of YB-1 expression on this unique Tip110 function. Initial experiments were performed to optimize the input amounts of LTR-CAT, Tat, Tip110 and YB-1 expression plasmids to achieve a lower level of basal level LTR promoter activity 


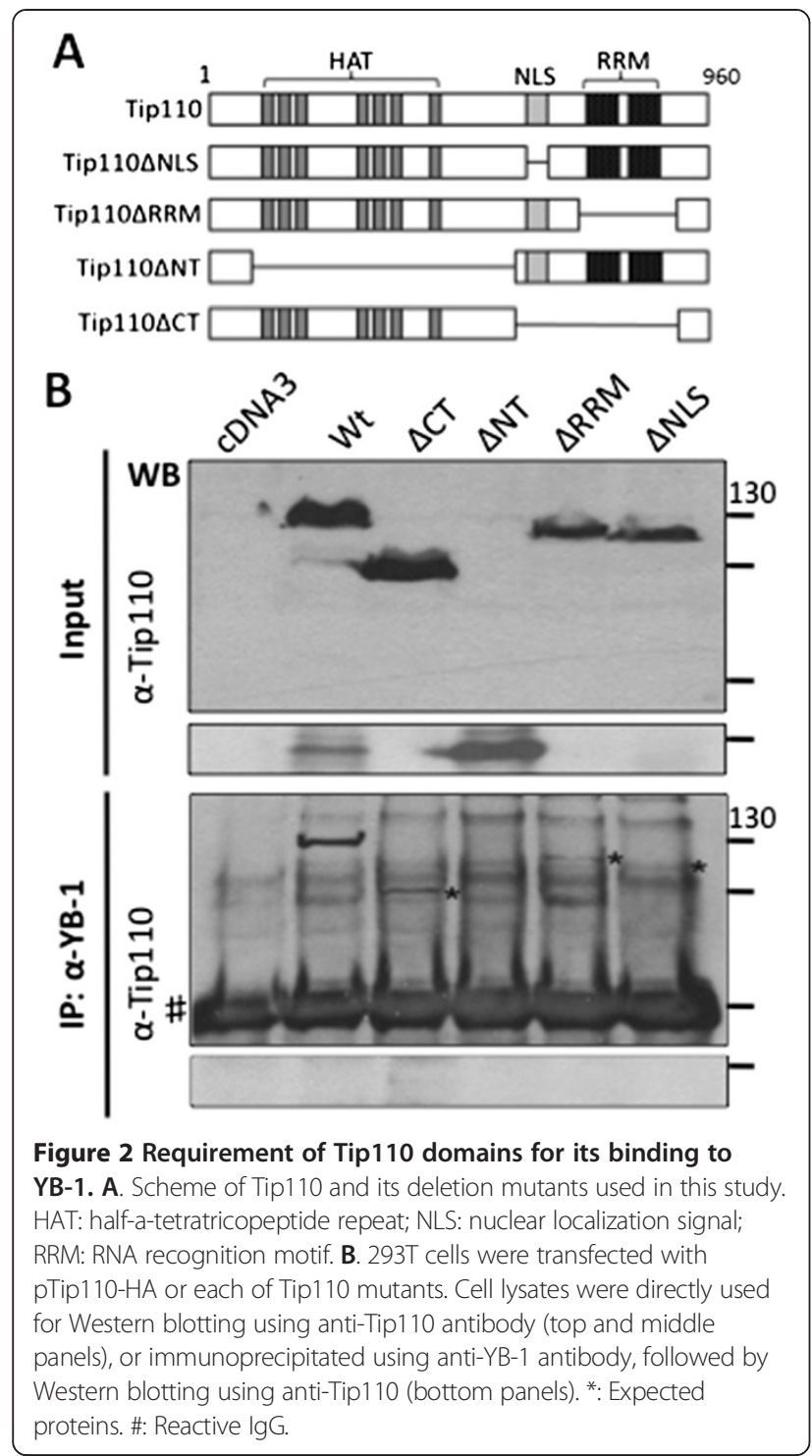

and a modest level of Tat transactivation activity on the LTR promoter (data not shown). We then transfected 293T cells with LTR-CAT, Tat, Tip110 and/or increasing amounts of YB-1 expression plasmids. pcDNA3 was used to equalize the total amount of DNA transfected, while pC3-GFP was included in the transfections to normalize the transfection variations. As expected [14,23], Tip110 or YB-1 expression increased Tat-mediated transactivation of the LTR promoter activity (Figure 4). In the presence of Tip110, increased YB-1 expression led to further increase in the Tatmediated LTR promoter activity. To further determine the relationship between the complex formation of Tip110 with YB-1 and YB-1 effects on Tip110/Tat-mediated transactivation of the LTR promoter, we performed similar experiments with both $\mathrm{YB}-1 \Delta \mathrm{N}$ and $\mathrm{YB}-1 \Delta \mathrm{C}$ mutants. $\mathrm{YB}-1 \Delta \mathrm{C}$ mutant expression led to little CAT activity, while $\mathrm{YB}-1 \Delta \mathrm{N}$ mutant showed similar CAT activity as the full-length YB-1.
These results suggest that YB-1 expression enhanced Tip110/Tat-mediated transactivation of the LTR promoter and suggest that the complex formation of Tip110 and YB1 is important for this function. The drastic reduction of the CAT activity in cells expressing $\mathrm{YB}-1 \Delta \mathrm{C}$ to a background level suggests that $\mathrm{YB}-1 \Delta \mathrm{C}$ may function in a dominant negative fashion.

\section{Tip110 promoted YB-1-mediated alternative splicing of} CD44 minigene

One of the well-characterized functions of YB-1 is regulation of the alternative splicing of the CD44 gene through interaction with the A/C-rich exon enhancer element [24].

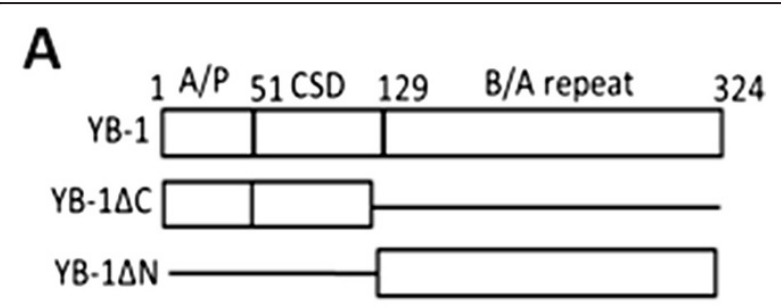

B

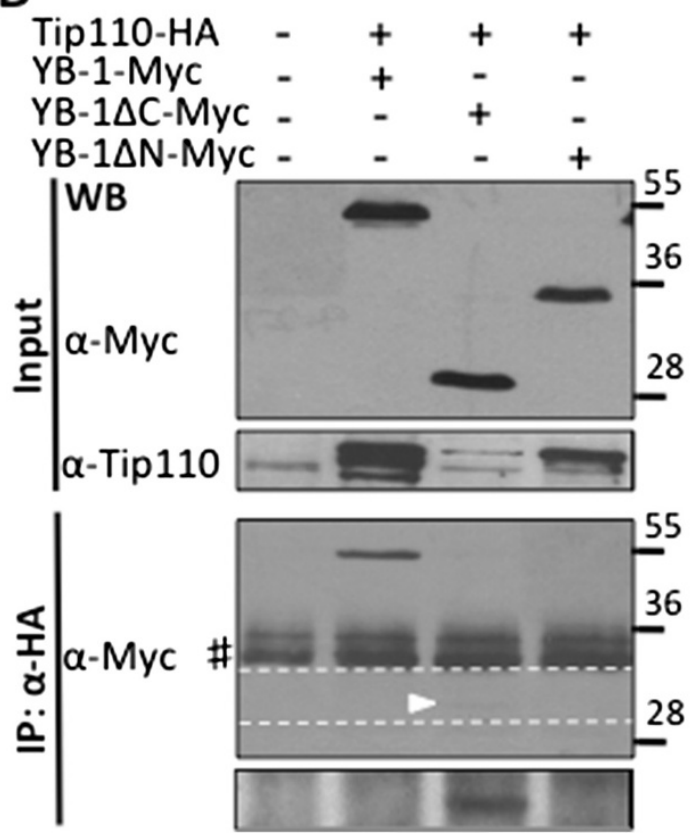

Figure 3 Requirement of YB-1 domains for its binding to Tip110. A. Scheme of YB-1 and its deletion mutants used in this study. A/P: Alanine/Proline rich; CSD: cold chock domain; B/A: basic/acidic repeats. B. 293T cells were transfected with pTip110-HA and pYB-1-Myc, or one of YB-1 mutants. Cell lysates were directly used for Western blotting using anti-Myc (top panel) or anti-Tip110 antibody (middle panel), or immunoprecipitated using anti-HA antibody, followed by Western blotting using anti-Myc (bottom panel). The long exposure of the area between the dotted lines was shown at the very bottom panel for the band marked by an arrowhead. \#: Reactive lgG. 


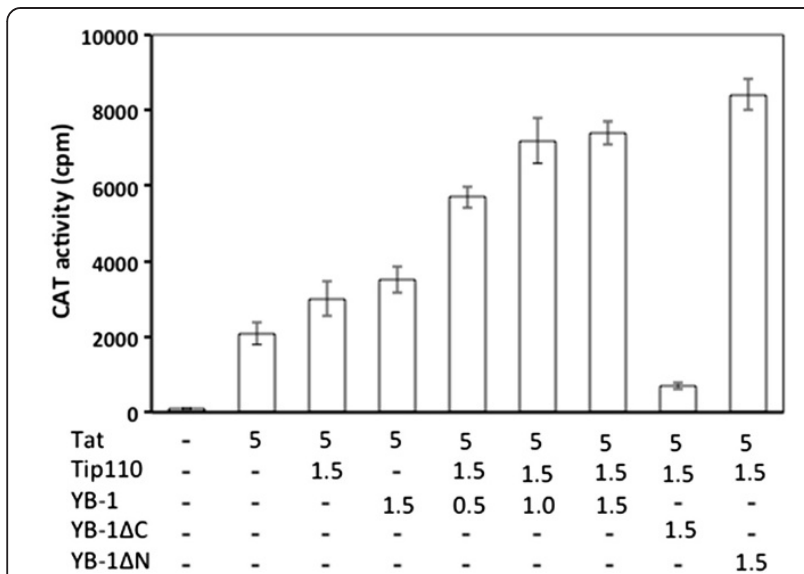

Figure 4 Effects of YB-1 expression on Tip110/Tat-mediated transactivation of the HIV-1 LTR promoter. 293T cells were transfected with $100 \mathrm{ng}$ of pLTR-CAT and various combinations of pTat-Myc, pTip110-HA, pYB-1-Myc, or each of YB-1 mutants. Input amounts of plasmids were shown at the top, all were in micrograms $(\mu \mathrm{g})$ with the except of pTat-Myc in nanograms (ng). pTat-Myc plasmid Cells were harvested $72 \mathrm{hr}$ post transfection for the CAT reporter gene activity assay. pCDNA3 plasmid was added to equalize the total amount of DNA transfected, while pC3-GFP plasmid was used to ensure the transfection efficiency among transfections. The data were mean \pm SD and representative of at least three independent experiments.

Therefore, we next determined the effects of Tip110 on YB-1-mediated CD44 alternative splicing. We took advantage of a CD44 minigene (Figure 5A) and performed in vivo RT-PCR-based splicing assay. Initial experiments were performed to optimize the input amount of CD44 minigene, YB-1 and Tip110 expression plasmids to ensure the RT-PCR-based detection of the alternative splicing (data not shown). As expected [24], YB-1 expression led to increased inclusion of the variable exon 5 (V5) of the CD44 minigene (Figure 5B, top panels). Tip110 expression alone appeared to have the similar enhancement effects. In the presence of YB-1, Tip110 increased inclusion of the $\mathrm{V} 5$ exon of $\mathrm{CD} 44$ minigene in a dose-dependent manner. Tip110 and YB-1 expression were determined by Western blotting to ensure that Tip110 expression did not alter YB-1 stability (Figure 5B, bottom panels). We next determined the requirement of Tip110 binding to YB-1 for this function. Similar in vivo splicing assay was performed with Tip $110 \Delta \mathrm{NT}$ and Tip110 $\Delta$ CT mutants. Compared to the full-length Tip110, Tip $110 \Delta$ NT and Tip110 $\Delta$ CT expression alone showed little changes in alternative splicing of the CD44 minigene (Figure 3C). Interestingly, in the presence of $\mathrm{YB}-1$, Tip $110 \Delta$ NT also showed little effects, while Tip $110 \Delta C T$ had considerable increase in V5 inclusion of the CD44 minigene. These results suggest that Tip110 binding with YB-1 plays some roles in YB-1 function.

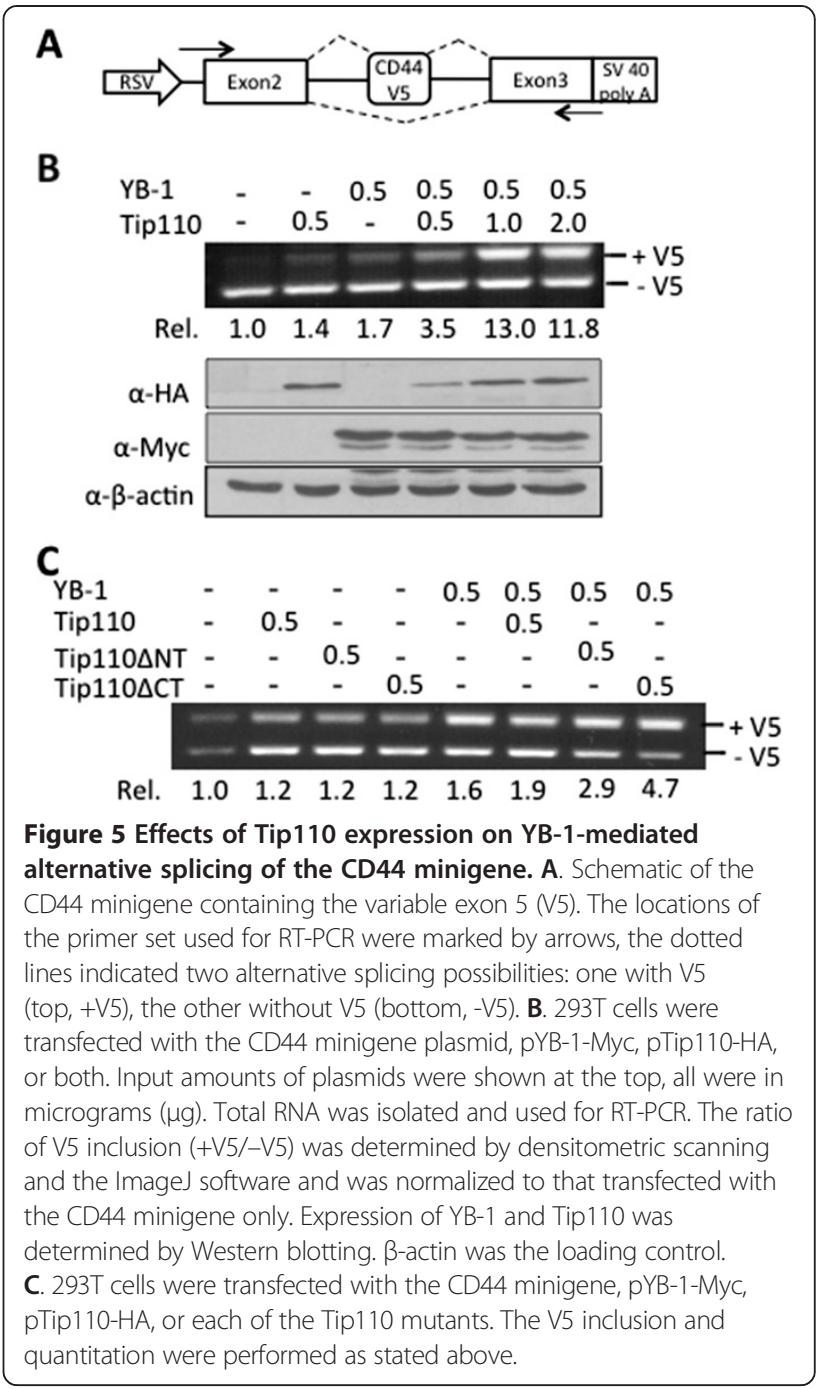

\section{Discussion}

In this study, we took the immunoaffinity approach to enrich the Tip110-binding proteins and identified those proteins by mass spectrometry. This was followed by further characterization of Tip110 interaction with YB-1, YB-1 effects on Tip110-mediated transactivation of the HIV-1 LTR promoter and Tip110 effects on YB-1-mediated alternative splicing of CD44 gene. The results showed that Tip110 bound to YB-1 in a specific manner and the interaction mutually regulated each other's function.

There were a total of 13 major cellular Tip110-binding proteins, which were grouped according to their function (Table 1). The group included cytoskeletal proteins, heat shock proteins, ribonucleoproteins, skin proteins and two ungrouped protein importin- $2 \alpha$ and YB-1. Each of those proteins likely contributes to either known or unknown biological function of Tip110. For example, Tip110 binding to cytoskeletal proteins and skin proteins may be involved in a Tip110-related skin keratinization 
disorder called porokertosis. A mutation in Tip110 gene has been linked to this disease [25-27]. It is conceivable that Tip110 function in RNA metabolism including premRNA splicing could require its interaction with ribonucleoproteins and heat shock proteins. The interaction of Tip110 with improtin- $2 \alpha$ could also regulate Tip110 nuclear translocation in different cells and under various physiological conditions. The biological significance of all those interactions clearly warrants further investigation.

We focused on Tip110/YB-1 interaction in this study. YB-1 is a multi-functional protein and plays important roles in transcriptional and translational regulation, DNA repair, drug resistance and stress responses to extracellular signals (for review, see [28]). YB-1 has recently been shown to regulate pre-mRNA splicing [29]. Co-immunoprecipitation studies with tagged proteins and immunoprecipitation of endogenous and exogenous YB-1 with overexpressed Tip110 in 293T cells confirmed this protein-protein interaction (Figure 1B \& C). Although Tip110 and YB-1 both contain RNA binding domains and have been shown to bind to RNA, the binding properties of Tip110 and YB-1 to each other were independent of RNA, as we showed that RNase A1 treatment in the cell lysates and during the immunoprecipitation did not alter their complex formation (data not shown). The specificity of the binding was further supported by the data obtained from mutagenesis analysis and showed that the N-terminal domains of both Tip110 and YB-1 were involved in the complex formation (Figures 2 and 3).

To investigate the functional relevance between the Tip110 and YB-1 interaction, we tested whether this complex formation affects transactivation of the HIV-1 LTR promoter and alternative splicing activity. Interaction of the HIV-1 Tat protein with its cognate RNA TAR is a prerequisite for Tat transactivation. Tip110 and YB-1 both interact with HIV-1 Tat viral protein and potentiate Tat transactivation in LTR-driven reporter gene assays [14,23]. Although YB-1 has only been shown to bind to the TAR region of the HIV-LTR, the synergistic effects of Tip110 are TAR-dependent, as these effects are attenuated by deletion of the TAR sequence from the HIV-1 LTR promoter. Based on these observations, we speculated that the Tip110/YB-1 complex affected the transactivation of HIV-1 LTR promoter activity. The LTR-CAT reporter gene assay showed that a fixed concentration of Tip110 combined with increasing concentrations of YB-1 resulted in a further increase in CAT activity (Figure 4), indicating that the Tip110/YB-1 complex modulates HIV-1 gene expression. The reporter gene assay with YB-1 mutants showed that expression of the YB-1 $\Delta C$ mutant abolished CAT activity, while expression of the YB- $1 \Delta \mathrm{N}$ mutant enhanced the activation to a greater extent than the full length YB-1. One interesting observation we found during the course of this study was that expression of the YB$1 \Delta \mathrm{C}$ mutant protein has a negative effect on Tip110 protein expression by Western blot (data not shown), which may explain the decrease in CAT activity. Furthermore, binding of Tat to YB-1 has been mapped to amino acids 75-203 in YB-1, while the YB- $1 \Delta \mathrm{C}$ mutant included amino acids $1-128$. Therefore, there is a stretch of 85 amino acids (residues 128-203) that are important for Tat binding, that are deleted in the $\mathrm{YB}-1 \Delta \mathrm{C}$ mutant, which may lead to the observed inhibition of CAT activity. Additional studies would be required to determine if the YB$1 \Delta \mathrm{C}$ mutant could be utilized to impair Tat function and effect HIV-1 gene expression.

Alternative splicing represents an important nuclear mechanism in the post-transcriptional regulation of gene expression. The role of YB-1 protein in the alternative splicing of $\mathrm{CD} 44$ is well documented in the literature. YB-1 binds to A/C-rich exon enhancers and stimulates splicing of the CD44 alternative variable exon 4 [24]. CD44 is essential to the physiological activities of normal cells, but they are also associated with the pathologic activities of cancer cells (for review, see [30]). Pre-mRNA from the human CD44 gene undergoes extensive alternative splicing within a cassette of at least 10 exons [31]. Increasing inclusion of these exons has been correlated to cancer and metastasis [32,33]. Here, we utilized a CD44 minigene (Figure 5A) to determine the physiological function of the Tip110/YB-1 interaction. Our results showed that overexpression of YB-1 and Tip110 together in 293T cells enhanced the inclusion of the variable exon 5 from the CD44 minigene (Figure 5B). Furthermore, the N-terminal domain of Tip110 (pTip110 $\Delta \mathrm{CT}$ ), which is involved in the interaction with YB-1, had higher alternative splicing activity than the C-terminal domain of Tip110 (pTip110 $\Delta$ NT). These results demonstrate the physiological significance of Tip110/YB-1 complex formation on the alternative splicing regulation of $\mathrm{CD} 44$.

\section{Conclusions}

There are a total of 13 cellular proteins that was identified by immunoaffinity purification followed by mass spectrometry. Among those is YB-1. Complex formation between Tip110 and YB-1 was confirmed by immunoprecipitation and Western blotting. Both $\mathrm{N}$ termini of Tip110 and YB-1 were found to be required for this complex formation. YB-1 expression enhanced Tip110mediated transactivation of HIV-1 LTR promoter, and Tip110 expression increased YB-1-mediated CD44 premRNA alternate splicing.

\section{Competing interests}

The authors declare that they have no competing interests. 


\section{Authors' contributions}

KT carried out the molecular genetic studies, participated in study design, and drafted the manuscript. YL participated in the study design and revised the manuscript. JJH conceived of the study, and participated in its design and coordination and helped to finalize the manuscript. All authors read and approved the final manuscript.

\section{Acknowledgements}

We would like to thank Dr. Stefan Stamm of University of Kentucky, Lexington, $\mathrm{KY}$ for generously providing us pCD44v5 minigene plasmid for the studies.

Received: 14 March 2013 Accepted: 2 July 2013

Published: 4 July 2013

\section{References}

1. Nagase T, Seki N, Tanaka A, Ishikawa K, Nomura N: Prediction of the coding sequences of unidentified human genes. IV. The coding sequences of 40 new genes (KIAA0121-KIAA0160) deduced by analysis of CDNA clones from human cell line KG-1. DNA Res 1995, 2(4):167-174.

2. Kawagoe N, Shintaku I, Yutani S, Etoh H, Matuoka K, Noda S, Itoh K: Expression of the SART3 tumor rejection antigen in renal cell carcinoma. J Urol 2000, 164(6):2090-2095.

3. Mizukoshi E, Nakamoto Y, Arai K, Yamashita T, Sakai A, Sakai Y, Kagaya T, Yamashita T, Honda M, Kaneko S: Comparative analysis of various tumorassociated antigen-specific t-cell responses in patients with hepatocellular carcinoma. Hepatology 2011, 53(4):1206-1216.

4. Murayama K, Kobayashi T, Imaizumi T, Matsunaga K, Kuramoto T, Shigemor $M$, Shichijo S, Itoh K: Expression of the SART3 tumor-rejection antigen in brain tumors and induction of cytotoxic T lymphocytes by its peptides. $J$ Immunother 2000, 23(5):511-518.

5. Niiya F, Nishizaka S, Matsunaga K, Koufuji K, Mori M, Katai H, Yamana H, Itoh K: Expression of SART3 tumor-rejection antigen in gastric cancers. Jpn J Cancer Res 2000, 91(3):337-342.

6. Sasatomi T, Suefuji Y, Matsunaga K, Yamana H, Miyagi Y, Araki Y, Ogata Y, Itoh K, Shirouzu K: Expression of tumor rejection antigens in colorectal carcinomas. Cancer 2002, 94(6):1636-1641.

7. Suefuji Y, Sasatomi T, Shichijo S, Nakagawa S, Deguchi H, Koga T, Kameyama T, Itoh K: Expression of SART3 antigen and induction of CTLs by SART3derived peptides in breast cancer patients. Br J Cancer 2001, 84(7):915-919.

8. Tsuda N, Murayama K, Ishida H, Matsunaga K, Komiya S, Itoh K, Yamada A: Expression of a newly defined tumor-rejection antigen SART3 in musculoskeletal tumors and induction of HLA class I-restricted cytotoxic T lymphocytes by SART3-derived peptides. J Orthop Res 2001, 19(3):346-351.

9. Yang D, Nakao M, Shichijo S, Sasatomi T, Takasu H, Matsumoto H, Mori K, Hayashi A, Yamana H, Shirouzu K, et al: Identification of a gene coding for a protein possessing shared tumor epitopes capable of inducing HLAA24-restricted cytotoxic T lymphocytes in cancer patients. Cancer Res 1999, 59(16):4056-4063.

10. Bell $M$, Schreiner $S$, Damianov A, Reddy R, Bindereif A: p110, a novel human U6 snRNP protein and U4/U6 snRNP recycling factor. EMBO J 2002, 21(11):2724-2735.

11. Medenbach J, Schreiner S, Liu S, Luhrmann R, Bindereif A: Human U4/U6 snRNP recycling factor p110: mutational analysis reveals the function of the tetratricopeptide repeat domain in recycling. Mol Cell Biol 2004, 24(17):7392-7401.

12. Liu Y, Timani K, Ou X, Broxmeyer HE, He JJ: C-MYC controlled TIP110 protein expression regulates OCT4 mRNA splicing in human embryonic stem cells. Stem Cells Dev 2012, 22(5):689-694.

13. Trede NS, Medenbach J, Damianov A, Hung LH, Weber GJ, Paw BH, Zhou Y, Hersey C, Zapata A, Keefe M, et al: Network of coregulated spliceosome components revealed by zebrafish mutant in recycling factor p 110 . Proc Natl Acad Sci USA 2007, 104(16):6608-6613.

14. Liu Y, Li J, Kim BO, Pace BS, He JJ: HIV-1 Tat protein-mediated transactivation of the HIV-1 long terminal repeat promoter is potentiated by a novel nuclear Tat-interacting protein of $110 \mathrm{kDa}$, Tip110. J Biol Chem 2002, 277(26):23854-23863.

15. Liu Y, Kim BO, Kao C, Jung C, Dalton JT, He JJ: Tip110, the human immunodeficiency virus type 1 (HIV-1) Tat-interacting protein of $110 \mathrm{kDa}$ as a negative regulator of androgen receptor (AR) transcriptional activation. J Biol Chem 2004, 279(21):21766-21773.
16. Liu Y, Timani K, Mantel C, Fan Y, Hangoc G, Cooper S, He JJ, Broxmeyer HE: TIP110/p110nrb/SART3/p110 regulation of hematopoiesis through CMYC. Blood 2011, 117(21):5643-5651

17. Liu Y, Lee MR, Timani K, He JJ, Broxmeyer HE: Tip110 maintains expression of pluripotent factors in and pluripotency of human embryonic stem cells. Stem Cells Dev 2012, 21(6):829-833.

18. Song EJ, Werner SL, Neubauer J, Stegmeier F, Aspden J, Rio D, Harper JW, Elledge SJ, Kirschner MW, Rape M: The Prp19 complex and the Usp4Sart3 deubiquitinating enzyme control reversible ubiquitination at the spliceosome. Genes Dev 2010, 24(13):1434-1447.

19. Deckert J, Hartmuth K, Boehringer D, Behzadnia N, Will CL, Kastner B, Stark $\mathrm{H}$, Urlaub H, Luhrmann R: Protein composition and electron microscopy structure of affinity-purified human spliceosomal B complexes isolated under physiological conditions. Mol Cell Biol 2006, 26(14):5528-5543.

20. Damianov A, Schreiner S, Bindereif A: Recycling of the U12-type spliceosome requires p110, a component of the U6atac snRNP. Mol Cell Biol 2004, 24(4):1700-1708.

21. Kuwano M, Oda Y, Izumi H, Yang SJ, Uchiumi T, Iwamoto Y, Toi M, Fujii T, Yamana $\mathrm{H}$, Kinoshita $\mathrm{H}$, et al: The role of nuclear $\mathrm{Y}$-box binding protein 1 as a global marker in drug resistance. Mol Cancer Ther 2004, 3(11):1485-1492.

22. Uramoto H, Izumi H, Ise T, Tada M, Uchiumi T, Kuwano M, Yasumoto K Funa K, Kohno K: p73 Interacts with c-Myc to regulate Y-box-binding protein-1 expression. J Biol Chem 2002, 277(35):31694-31702.

23. Ansari $S A$, Safak M, Gallia GL, Sawaya BE, Amini S, Khalili K: Interaction of YB-1 with human immunodeficiency virus type 1 Tat and TAR RNA modulates viral promoter activity. J Gen Virol 1999, 80(Pt 10):2629-2638.

24. Stickeler E, Fraser SD, Honig A, Chen AL, Berget SM, Cooper TA: The RNA binding protein YB-1 binds A/C-rich exon enhancers and stimulates splicing of the CD44 alternative exon v4. EMBO J 2001, 20(14):3821-3830.

25. Zhang ZH, Wang ZM, Crosby ME, Kang KF, Luan J, Huang W, Xiang LH, Zheng ZZ: Reassessment of microarray expression data of porokeratosis by quantitative real-time polymerase chain reaction. J Cutan Pathol 2010, 37(3):371-375.

26. Zhang ZH, Niu ZM, Yuan WT, Zhao JJ, Jiang FX, Zhang J, Chai B, Cui F, Chen W, Lian CH, et al: A mutation in SART3 gene in a Chinese pedigree with disseminated superficial actinic porokeratosis. Br J Dermatol 2005, 152(4):658-663.

27. Liu P, Zhang S, Yao Q, Liu X, Wang X, Huang C, Huang X, Wang P, Yuan M, Liu JY, et al: Identification of a genetic locus for autosomal dominant disseminated superficial actinic porokeratosis on chromosome 1p31.3p31.1. Hum Genet 2008, 123(5):507-513.

28. Kohno K, Izumi H, Uchiumi T, Ashizuka M, Kuwano M: The pleiotropic functions of the Y-box-binding protein, YB-1. BioEssays 2003, 25(7):691-698.

29. Wei WJ, Mu SR, Heiner M, Fu X, Cao LJ, Gong XF, Bindereif A, Hui J: YB-1 binds to CAUC motifs and stimulates exon inclusion by enhancing the recruitment of U2AF to weak polypyrimidine tracts. Nucleic Acids Res 2012, 40(17):8622-8636.

30. Naor D, Nedvetzki S, Golan I, Melnik L, Faitelson Y: CD44 in cancer. Crit Rev Clin Lab Sci 2002, 39(6):527-579.

31. Mackay CR, Terpe HJ, Stauder R, Marston WL, Stark H, Gunthert U: Expression and modulation of CD44 variant isoforms in humans. J Cell Biol 1994, 124(1-2):71-82

32. Fox SB, Fawcett J, Jackson DG, Collins I, Gatter KC, Harris AL, Gearing A, Simmons DL: Normal human tissues, in addition to some tumors, express multiple different CD44 isoforms. Cancer Res 1994, 54(16):4539-4546.

33. Gunthert U, Hofmann M, Rudy W, Reber S, Zoller M, Haussmann I, Matzku S, Wenzel A, Ponta $\mathrm{H}$, Herrlich P: A new variant of glycoprotein CD44 confers metastatic potential to rat carcinoma cells. Cell 1991, 65(1):13-24.

doi:10.1186/1471-2199-14-14

Cite this article as: Timani et al: Tip110 interacts with YB-1 and regulates each other's function. BMC Molecular Biology 2013 14:14. 